\title{
Thyroid ultrasound is the best prevalence indicator for assessment of iodine deficiency disorders: a study in rural/ tribal schoolchildren from Gujarat (Western India)
}

\author{
Sheela Brahmbhatt, Rajesh M Brahmbhatt and Steven C Boyages \\ Department of Diabetes and Endocrinology, Westmead Hospital, Westmead, Australia \\ (Correspondence should be addressed to S R Brahmbhatt, Department of Diabetes and Endocrinology, Westmead Hospital, Westmead, \\ New South Wales 2145 Australia; Email: sheelab@westgate.wh.usyd.edu.au) \\ (Requests for offprints should be addressed to S C Boyages, Department of Diabetes and Endocrinology, Westmead Hospital, Westmead, \\ New South Wales 2145 Australia)
}

\begin{abstract}
Objectives: (i) To assess the severity of iodine deficiency disorders (IDD), (ii) to determine the aetiology of IDD in Gujarat, (iii) to identify the best prevalence indicator of IDD, and (iv) to compare thyroid volume (TV) results with the WHO International reference.

Methods: Five hundred and thirty schoolchildren (6-15 years) were studied from two districts (Baroda and Dang) and data were collected on dietary habits and parameters such as height, weight, thyroid size by palpation and ultrasonography, urinary iodine (UI), and blood thyroid stimulating hormone (TSH). Drinking water was analyzed for iodine content and food articles for goitrogens.

Results: In Gujarat children median UI (interquartile range) $=56 \quad(30-96) \mu \mathrm{g} / \mathrm{l}$, mean $\mathrm{TSH}=1.71 \pm 2.10 \mathrm{mU} / \mathrm{l}$, goiter by palpation $=30 \%$, and median TV $=27.8(23-35) \mathrm{ml}$. Females had lower median UI $(48(27-82) \mu \mathrm{g} / \mathrm{l})$ and higher mean TSH levels $(2.0 \pm 2.5 \mathrm{mU} / \mathrm{l})$ than males. Applying the WHO ultrasonography reference to Gujarat children resulted in an enlarged TV-for-body surface area in almost $100 \%$ of subjects. Ninety-nine percent of females and $95 \%$ of males had enlarged TV-for-age. Three to eight times larger TV were seen in all subjects as compared with European children. Dang children were severely malnourished. Flavonoids like vitexin, glucosyl vitexin and apigenin were detected in pearl millet. Apigenin was never identified in pearl millet. Dang district water was lacking in iodine content.

Conclusions: IDD is a severe public health problem in Gujarat. Baroda district is a new pocket of IDD. High amounts of dietary flavonoids in Baroda and Dang districts, and lack of iodine in Dang water, account for IDD. TV measurement by ultrasound is the best prevalence indicator of IDD.
\end{abstract}

European Journal of Endocrinology 143 37-46

\section{Introduction}

Iodine deficiency is one of the oldest and most insidious of human health disorders and the fight against iodine deficiency remains one of the major public health challenges at the end of the 20th century (1). Iodine deficiency may either act alone or in concert with other environmental factors to produce a spectrum of clinical conditions - iodine deficiency disorders (IDD). These environmental factors include dietary substances that interfere with normal thyroid function and promote thyroid growth (termed goitrogens).

Endemic goiter reflects the adaptive response of the thyroid to a lack of iodine. Although the thyroid gland may become very enlarged it is not usually associated with morbidity. By contrast, the most damaging and pernicious effect of iodine deficiency is on the developing brain, an effect mediated by perturbations to maternal and fetal thyroid hormone homeostasis (2). All iodine deficiency disorders are preventable. Although iodine supplementation programs have been implemented in various countries since 1924 , IDD remains a significant world health problem. According to a recent WHO (1999) report on global status of IDD, two billion people are at risk (3). The major health organizations have determined agreed criteria for a population to be considered iodine replete (1). Although the technology and methods of implementation of iodine supplementation programs are relatively simple, the monitoring and timely assessments of such programs are more difficult.

This is, in part, related to the low sensitivity and low specificity of monitoring methods. The two commonest 
methods of monitoring are urinary iodine estimation (UIE) and childhood goiter rate (assessed by palpation). UIE is used as an indicator of present iodine intake, whereas goiter rate indicates past history of iodine deficiency. Although there have been several reports highlighting the pitfalls of both methods, there are few studies that have applied each method to a population group, and specifically in areas where confounding factors such as high goitrogen intake and malnutrition may be significant.

The aims of the present study were: (i) to assess the severity of IDD in Gujarat (Western India) by testing various prevalence indicators of IDD in this population; (ii) to determine the relative contribution of nutritional iodine deficiency and goitrogens as causative factors in the aetiology of goiter in this region; (iii) to identify the best prevalence indicator of IDD and (iv) to describe thyroid volumes measured by ultrasonography in Gujarat schoolchildren and compare these with European schoolchildren (WHO has recently adopted thyroid volume ultrasonography results from European schoolchildren as the international reference (4)).

\section{Subjects and methods}

\section{Background and geography}

Endemic goiter and cretinism are widely distributed over the subcontinent of India in a broad Himalayan and sub-Himalayan belt. A conservative estimate suggests that about 150 million people are at risk of IDD, 54 million have goiter, 2.2 million suffer from cretinism and an estimated 6.6 million are affected by milder neurological deficits attributable to environmental iodine deficiency (5). The Gujarat state has nineteen districts and a population of about 42 million, consisting of both urban and rural segments in most of the districts. Dang district has a predominantly tribal population (Fig. 1). The majority of the rural and tribal populations belong to a low socioeconomic stratum of the society. Baroda district has never been investigated for IDD in the past but in Dang district the goiter prevalence by palpation was found to be $40 \%$ (6), and the sale of non-iodized salt has been banned since this survey in 1994.

\section{Diet}

The majority of the population of Gujarat is mainly vegetarian and the diet consists of cereals like pearl millet, jowar, wheat and rice, pulses (tuver dal and udad) and vegetables like onion, chili, ginger, garlic, cabbage and beans. In addition to cereals, pulses and vegetables consumed by the rural population, the tribal population from Dang consumed nagli (a cereal), kharsani (type of oil used for cooking) and bamboo shoots as vegetables. The main evening meal for both the tribal and rural populations consists of pearl millet pancakes.

\section{Population studied}

Five hundred and thirty schoolchildren aged 6-15 years were selected randomly by home surveys (118 rural schoolchildren from Muval and Tentalav - two villages in the Baroda district) and school visits (412 tribal children from Dang). The study group comprised 283 boys and 247 girls (M:F ratio $=1.15: 1$ ) (see Table 1). Figure 2 shows their age distribution. Information on sex, height and weight was recorded and the body surface area (BSA) was calculated by using the formula (7):

$$
\begin{aligned}
& \text { BSA }\left(\mathrm{m}^{2}=\text { weight }(\mathrm{kg})^{0.425} \times \text { height }(\mathrm{cm})^{0.725}\right. \\
& \times 71.84 \times 10^{-4}
\end{aligned}
$$

The IDD status was measured by clinical (thyroid size) and biochemical indicators. Palpation (1) and ultrasonography (8) that measured thyroid volume (TV) scored thyroid size. Random urine samples for urinary iodine (UI) and blood spots for thyroid stimulating hormone (TSH) determination were collected from all subjects.

\section{Thyroid palpation}

A simplified classification of three goiter grades (a modification of the previous classification having five grades) as defined by WHO (1) was used: grade 0 , no palpable or visible goiter; grade 1, palpable but not visible; grade 2 , visible goiter when the neck is in the normal position. Thyroid palpation to determine thyroid size is less reliable in children $(9,10)$.

\section{Thyroid ultrasonography}

The availability of portable ultrasound equipment has facilitated its application to define goiter size in epidemiological field studies $(10,11)$. It gives a quantitative measure of TV that is largely free of observer bias.

Ultrasound scanning for TV determinations was carried out as recommended (8) using an Ausonics portable ultrasound machine with a standard $5.0 \mathrm{MHz}$ transducer. Longitudinal and transverse scans were performed allowing the measurement of the thickness, the width, and the length of each lobe. The volume (V) of each lobe was calculated by two formulae $(4,10)$.

WHO formula: $\mathrm{V}(\mathrm{ml})=0.000479 \times$ length $(\mathrm{mm})$ $\times$ width $(\mathrm{mm}) \times$ thickness $(\mathrm{mm})$.

Rotation ellipsoid model formula: $\mathrm{V}(\mathrm{ml})=0.00052 \times$ length $(\mathrm{mm}) \times$ width $(\mathrm{mm}) \times$ thickness $(\mathrm{mm})$.

Thyroid volume was calculated as the sum of the volumes of both lobes. The volume of the isthmus was not included. Thyroid glands were classified as 'normal' or 'enlarged' using the WHO reference (thyroid volumefor-age (TV-for-age) and thyroid volume-for-body surface area (TV-for-BSA) (4)). Thyroid volumes greater than the 97 th percentile values were considered 
abnormally large and those less than or equal to the 97th percentile values as normal. Statistical evaluation was performed by linear regression analysis. Determination of TV by ultrasonography can show an interobserver error of up to $30 \%$ and intraobserver variation of $2-15 \%$ (12). A single observer (R MB) was used in the determination of TV in this study.

\section{Urinary iodine}

UI estimations were performed by a modified acid digestion method (method E), based on the reaction between cerium IV and arsenic III (Sandell-Kolthoff reaction) using a Technicon Autoanalyzer II (13). The results were expressed as micrograms of iodine per liter $(\mu \mathrm{g} / \mathrm{l})$.

\section{Blood spot TSH}

Blood spot TSH levels were measured using commercially available Bioclone neonatal TSH ELISA kits (Bioclone Australia Pty Limited, Marrickville, NSW, Australia) for the quantitative determination of TSH in human neonatal blood spots.
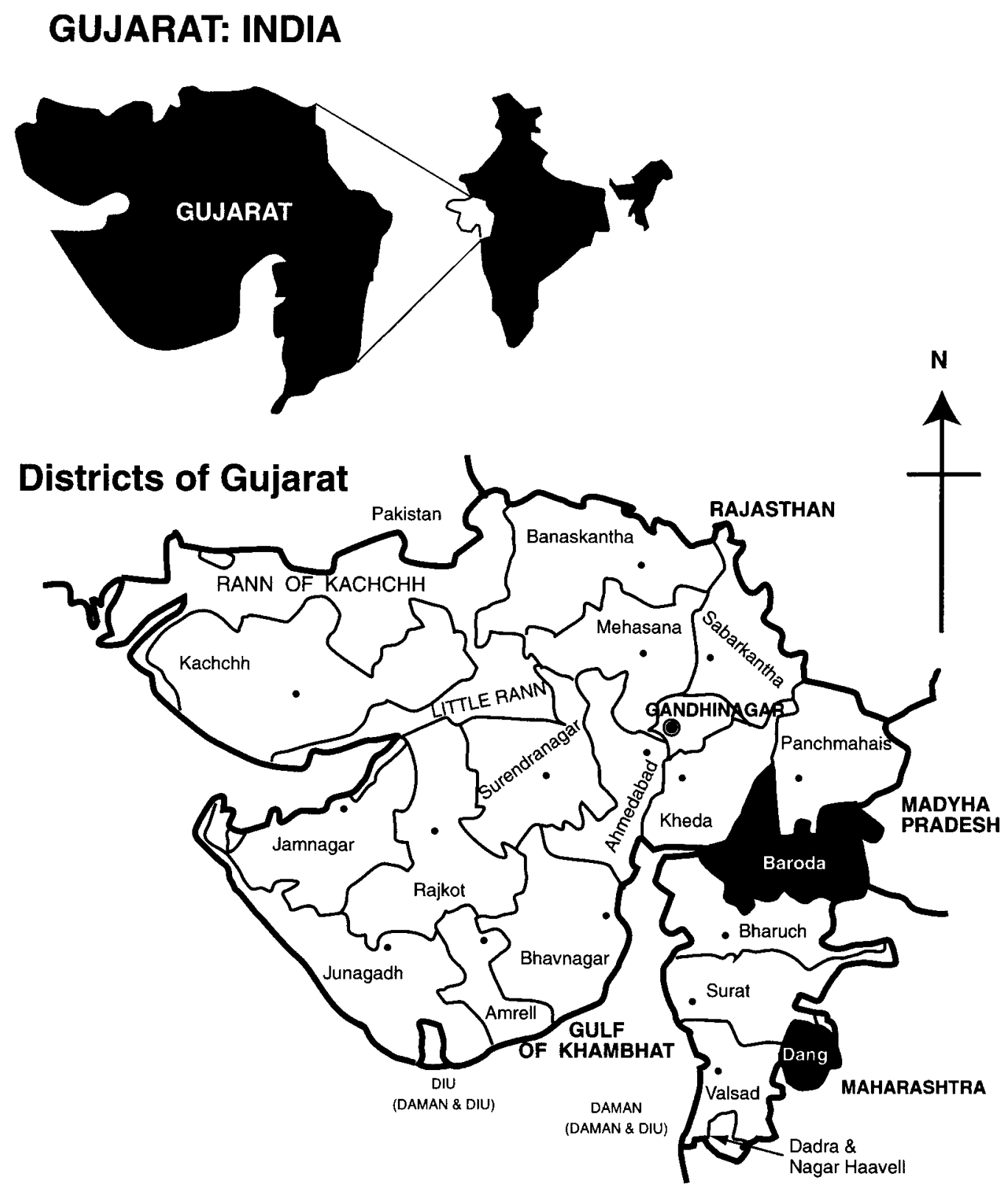

Figure 1 Map of Gujarat state, shown as a part of India, with the area of study - Baroda and Dang - as shaded districts. 


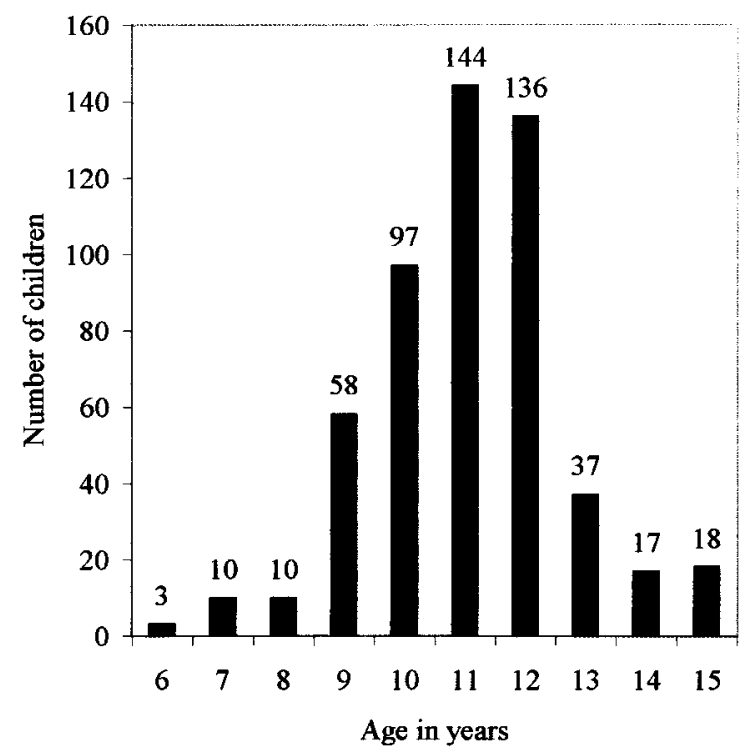

Figure 2 Graph showing age distribution of schoolchildren in the described range. The numbers above the columns specify exact number of subjects in each age group.

\section{Dietary goitrogens analysis}

Cereal grains were powdered and subjected to soxhlet extraction for $3 \mathrm{~h}$ using methanol as the extracting solvent. The extracts were then analyzed by liquid chromatography-mass spectrophotometry without any attempt to pre-concentrate. The mass spectrometer (Hewlett Packard-1100) was operated in selected ion monitoring mode to monitor ions such as 433 (vitexin), 449 (luteolin-7-glucoside), 565 (aplin), 287 (luteolin) and 271 (apigenin).

\section{Statistical methods}

Proportion, mean, standard deviation, median and interquartile (IQ) range have been used to describe the data where appropriate. Statistical analyses were performed using SPSS software version 6.1.2.

\section{Results}

Male and female children of Gujarat, from the Dang and Baroda districts had similar distributions for variables of age, height, weight, and BSA. Although BSA did not show a significant difference between the two districts $(P=0.6)$, body mass index (BMI) was significantly lower for the children from the Dang district compared with children from the Baroda district $(P<0.0001)$ (Table 1). These effects are probably explained by a greater degree of malnutrition in the Dang children. Iodine content of drinking water was adequate $(32 \mu \mathrm{g} / \mathrm{l})$ in the Baroda district while it was lacking $(0 \mu \mathrm{g} / \mathrm{l})$ in the Dang district (Table 2).

The median (and IQ range) UI for all children from Gujarat was 56 (30-96) $\mu \mathrm{g} / \mathrm{l}$. Children from Dang had lower median UI concentrations (50 (27-90) $\mu \mathrm{g} / \mathrm{l})$ as compared with Baroda children (median UI $=79(48-$ 117) $\mu \mathrm{g} / \mathrm{l})$. Based on these values the Dang district would be categorized as having moderate iodine deficiency and the Baroda district as having mild iodine deficiency. Statistically highly significant gender differences were noted in median urinary iodine values, with females from both districts being more severely affected $(P=0.01)$ (Table 1$)$. The frequency distribution of the severity of iodine deficiency for male and female children from the Dang and Baroda districts is shown in Fig. 3. Fifty-four percent of females and 45\% of males from the Dang district had UI levels below $50 \mu \mathrm{g} / \mathrm{l}$ (ideally $<20 \%$ of samples should be below $50 \mu \mathrm{g} / \mathrm{l}(1))$. By contrast, in the Baroda district $35 \%$ of females and $25 \%$ of males had UI levels below $50 \mu \mathrm{g} / \mathrm{l}$.

The Gujarat children had a relatively high mean blood TSH level of $1.71 \pm 2.10 \mathrm{mU} / \mathrm{l}$. The blood TSH levels were significantly different in boys and girls $(P=0.01)$ from the Dang district but not in those from the Baroda district $(P=0.59)$. Females were more likely to have elevated TSH values (Table 1). Blood spot TSH values $>5 \mathrm{mU} / \mathrm{l}$ were seen in $5 \%$ of girls and $3 \%$ of boys from the Dang district and $4 \%$ of both sexes from the Baroda district. TSH values $>3 \mathrm{mU} / \mathrm{l}$ were noted in $30 \%$ of girls and $27 \%$ of boys from Dang and $21 \%$ of girls and $11 \%$ of boys from Baroda. Figure 4A (Dang) and 4B (Baroda) show the frequency distribution of TSH values by sex for the described ranges. TSH distribution curves were shifted to the right in children from the Dang district as compared with those from the Baroda district (Fig. 4A,B and Table 1). There have been no population normative values for TSH published for this population nor for schoolchildren from an iodine-replete environment.

Goiter by palpation was found in 157 out of 530 (30\%) children with most of them having grade 1 goiter according to the WHO classification. Grade 2 goiter was seen in two boys. In the Dang district, goiter was palpable in $36 \%$ of children whereas in the Baroda district, goiter was palpable in $6 \%$ of children (Table 2).

Median TV measured by ultrasonography was 27.8 $(23-35) \mathrm{ml}$. Enlarged TV-for-BSA was seen in almost $100 \%$ of schoolchildren. TV-for-age above the 97th percentile (WHO) was seen in $99 \%$ of children from the Dang district and $91 \%$ of children from the Baroda district. Ninety-nine percent of girls and 95\% of boys had enlarged TV-for-age (Table 2). Although both the districts revealed a high prevalence of goiter by ultrasound (TV calculated by both the formulae), thyroid volumes were significantly higher $(P<0.001)$ in the Dang district compared with rural subjects from the Baroda district (Table 1). Gender wise, TV was significantly different in the Dang district with boys having larger thyroids, but this was not seen in the Baroda district children $(P=0.003$ and $P=0.2$ respectively). Clinically, this gender difference was not significant in the Dang district. Median values for 
Table 1 District and sex wise distribution of clinical, biochemical and anthropometric parameters.

\begin{tabular}{|c|c|c|c|c|c|c|c|}
\hline Parameter & Range & Mean \pm S.D. & Median (IQ) & Range & Mean \pm S.D. & Median (IQ) & $\boldsymbol{P}$ \\
\hline Baroda $(n=118)$ & & Girls $(n=28)$ & & & Boys $(n=90)$ & & \\
\hline Age (years) & $6-15$ & $11.7 \pm 2.3$ & $12(11-13)$ & $6-15$ & $11.6 \pm 2.5$ & $12(10-13)$ & NS \\
\hline Height (cm) & $80-154$ & $124 \pm 19.6$ & $129(109-138)$ & $76-164$ & $127 \pm 18.3$ & $130(119-140)$ & NS \\
\hline Weight (kg) & $13-46$ & $27 \pm 7$ & $27(22-31)$ & $15-45$ & $26 \pm 7$ & $25(20-30)$ & NS \\
\hline $\operatorname{BSA}\left(\mathrm{m}^{2}\right)$ & $0.6-1.36$ & $0.95 \pm 0.2$ & $0.93(0.8-1.1)$ & $0.5-1.37$ & $0.96 \pm 0.2$ & $0.93(0.8-1.4)$ & NS \\
\hline BMI $\left(\mathrm{kg} / \mathrm{m}^{2}\right)$ & $9.3-38$ & $18.5 \pm 8$ & $16(13-20)$ & $9.6-32$ & $16.5 \pm 5$ & $14(13-18.6)$ & NS \\
\hline UI $(\mu \mathrm{g} / \mathrm{l})$ & $0-190$ & $69 \pm 49$ & $63.5(30-92)$ & $0-400$ & $98 \pm 65$ & $84(54-120)$ & 0.01 \\
\hline TSH (mU/l) & $0-25$ & $2.35 \pm 5.15$ & $1.13(0.3-2.5)$ & $0-8$ & $1.2 \pm 1.4$ & $0.8(0.2-1.5)$ & 0.59 \\
\hline TV $1(\mathrm{ml})^{*}$ & $8-40.5$ & $25.0 \pm 9.6$ & $28.2(17-31)$ & $6.5-56$ & $23 \pm 12$ & $20(13-32)$ & 0.2 \\
\hline TV $2(\mathrm{ml})^{\star \star}$ & $8.7-44$ & $27.1 \pm 10$ & $30.7(19-34)$ & $7-61$ & $25 \pm 13$ & $22(14-35)$ & 0.2 \\
\hline Dang $(n=412)$ & & Girls $(n=219)$ & & & Boys $(n=193)$ & & \\
\hline Age (years) & $6-15$ & $11 \pm 1$ & $11(10-12)$ & $8.0-15$ & $11 \pm 1$ & $11(10-12)$ & NS \\
\hline Height (cm) & $112-149$ & $131 \pm 7$ & $131(126-136)$ & $112-164$ & $131 \pm 9$ & $130(126-136)$ & NS \\
\hline Weight (kg) & $9-40$ & $23 \pm 4.5$ & $23(20-25)$ & $11-47$ & $23 \pm 4.7$ & $23(20-25)$ & NS \\
\hline $\operatorname{BSA}\left(\mathrm{m}^{2}\right)$ & $0.7-1.3$ & $0.93 \pm 0.11$ & $0.93(0.9-1.0)$ & $0.7-1.46$ & $0.94 \pm 0.12$ & $0.9(0.86-1.0)$ & NS \\
\hline BMI $\left(\mathrm{kg} / \mathrm{m}^{2}\right)$ & $10.5-18$ & $13.2 \pm 1.4$ & $13.2(12-14)$ & $7.0-18$ & $13.3 \pm 1.4$ & $13.2(12.6-14)$ & NS \\
\hline UI $(\mu \mathrm{g} / \mathrm{l})$ & $0-288$ & $58 \pm 46$ & $48(27-80)$ & $0-336$ & $72 \pm 56$ & $57(30-108)$ & 0.01 \\
\hline TSH (mU/l) & $0-12$ & $1.96 \pm 2.05$ & $1.58(0.3-3.1)$ & $0.0-6$ & $1.5 \pm 1.6$ & $1.0(0-3)$ & 0.01 \\
\hline TV $1(\mathrm{ml})^{*}$ & $11-112$ & $27.4 \pm 11.5$ & $25(21-31.6)$ & $11.6-84$ & $29 \pm 9$ & 27 (23-33) & 0.003 \\
\hline TV $2(\mathrm{ml})^{\star \star}$ & $12-121$ & $29.7 \pm 12.5$ & $27(23-34)$ & 13-91.6 & $31.6 \pm 9.8$ & $30(25-36)$ & 0.003 \\
\hline
\end{tabular}

* Thyroid volume derived by WHO formula (3), ${ }^{* *}$ thyroid volume by rotation ellipsoid model formula (9).

NS = not significant.

thyroid volumes were significantly higher $(P<0.02)$ in Tentalav than Muval, two villages in the Baroda district.

Cereals like wheat, rice, pearl millet, jowar, nagli, and pulses like tuver dal and udad were examined for the presence of dietary goitrogens. We identified various flavonoids like apigenin, vitexin and glucosyl vitexin in pearl millet. The quantity of vitexin and apigenin was highest in pearl millet from Tentalav (Table 3). In other cereals, flavonoids were not identified. Other goitrogens were detected from Dang district kharsani oil, but they remain unidentified.

There was a weak but statistically significant positive correlation $(P<0.01)$ between thyroid volume and BSA, weight and height ( $r=0.17,0.10$ and 0.2 respectively), whilst BMI and UI showed no significant correlation $(r=0.06)$ with the thyroid volume $(P=0.17)$. However, a logarithmic regression of thyroid volume against BMI showed a weak correlation $(r=-0.11$ and $P=0.009)$. The best fitting multivariate linear regression model for thyroid volume selected using backward elimination accounted for only $15 \%\left(\mathrm{R}^{2}\right)$ of the variability in thyroid volume, as shown in Table 4.

The BSA of children from Gujarat is much lower in comparison to European children. The TV-for-age and TV-for-BSA of Gujarat schoolchildren (both males and females) were from 3 to 8 times higher compared with the 50th and 97th percentile values for iodine-replete European schoolchildren including the WHO reference norms (Tables 5 and 6). However, the comparisons could be made only for children with $\mathrm{BSA}=0.8$ to $1.2 \mathrm{~m}^{2}$ (note: $9 \%$ of our study population had BSA $<0.8 \mathrm{~m}^{2}$ and only $1 \%$ had BSA $>1.2 \mathrm{~m}^{2}$ ).

\section{Discussion}

We used all prevalence indicators and epidemiological criteria to assess the severity of IDD in the state of Gujarat, aiming at a large target population of schoolchildren.

Table 2 Thyroid size as determined by palpation or ultrasound (WHO).

\begin{tabular}{lcccc}
\hline Goitre & $\begin{array}{c}\text { Male } \\
n(\%)\end{array}$ & $\begin{array}{c}\text { Female } \\
n(\%)\end{array}$ & $\begin{array}{c}\text { Baroda } \\
n(\%)\end{array}$ & $\begin{array}{c}\text { Dang } \\
n(\%)\end{array}$ \\
\hline Thyroid palpation & & & & \\
$\quad$ Grade 0 & $196(69)$ & $177(72)$ & $111(94)$ & $262(63.6)$ \\
$\quad$ Grade 1 & $85(30)$ & $70(28)$ & $7(6)$ & $148(35.7)$ \\
$\quad$ Grade 2 & $2(1)$ & $0(0)$ & $0(0)$ & $2(0.7)$ \\
Total $(n=530)$ & $283(100)$ & $247(100)$ & $118(100)$ & $412(100)$ \\
Thyroid ultrasound & $269(95)$ & $245(99)$ & $107(91)$ & $407(99)$ \\
$\quad$ Enlarged thyroid volume-for-age & $282(\sim 100)$ & $247(100)$ & $117(\sim 100)$ & $412(100)$ \\
$\quad$ Enlarged thyroid volume-for-BSA & - & - & 0 \\
lodine content in water $(\mu \mathrm{g} / \mathrm{l})$ & & &
\end{tabular}



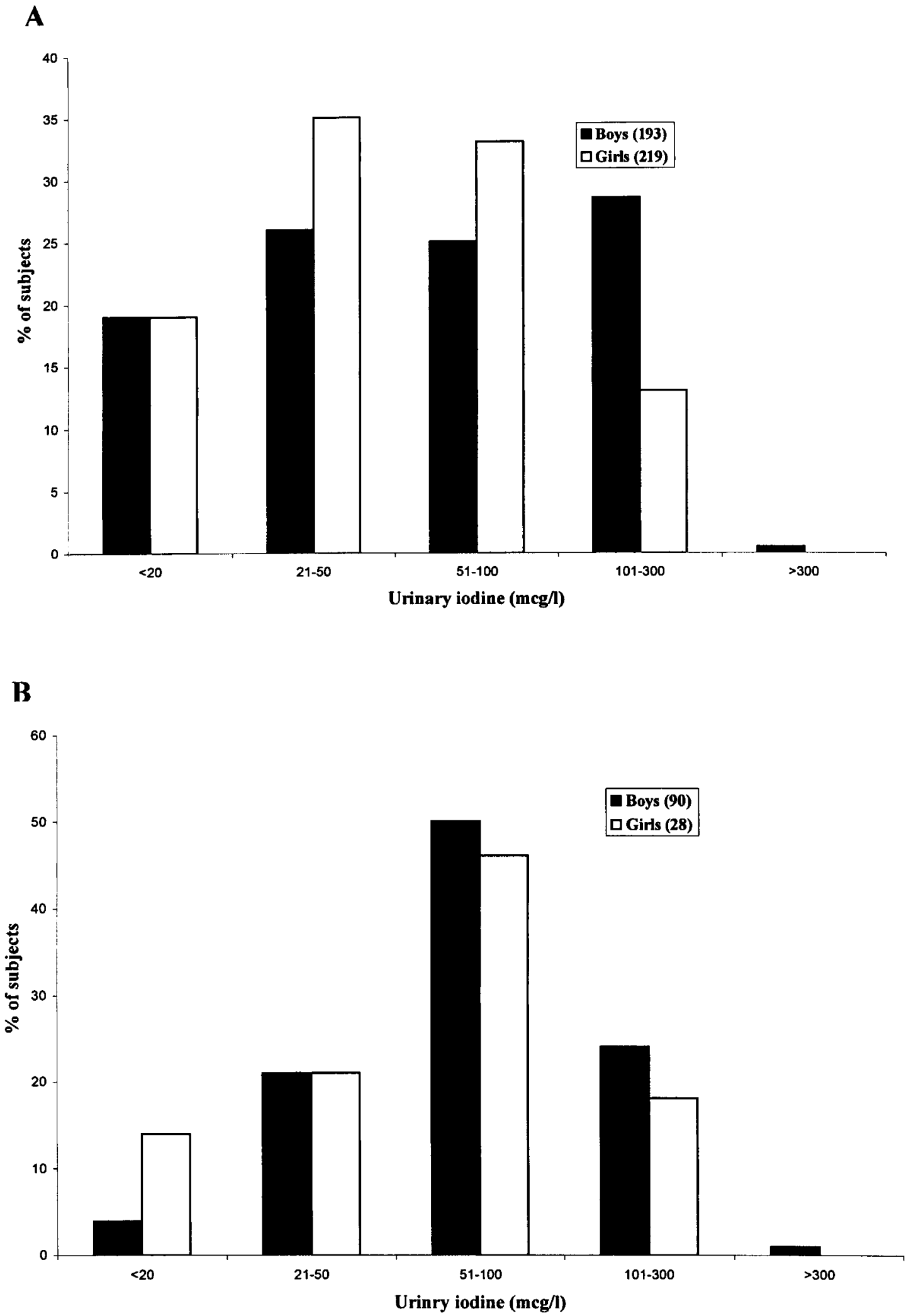

Figure 3 Frequency distribution of urinary iodine $(\mu \mathrm{g} / \mathrm{l})$ in boys and girls from (A) Dang district and (B) Baroda district. 
A

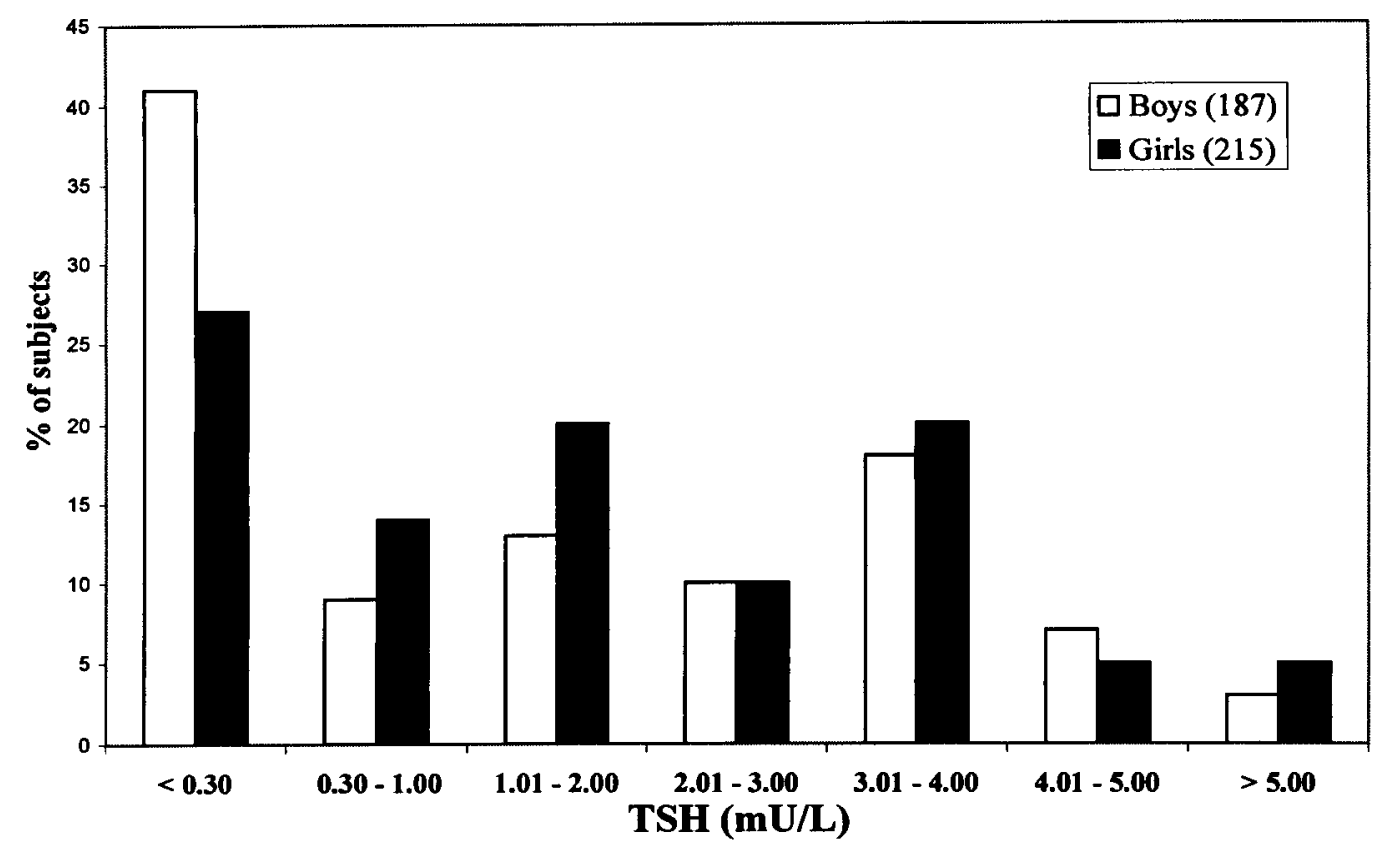

B

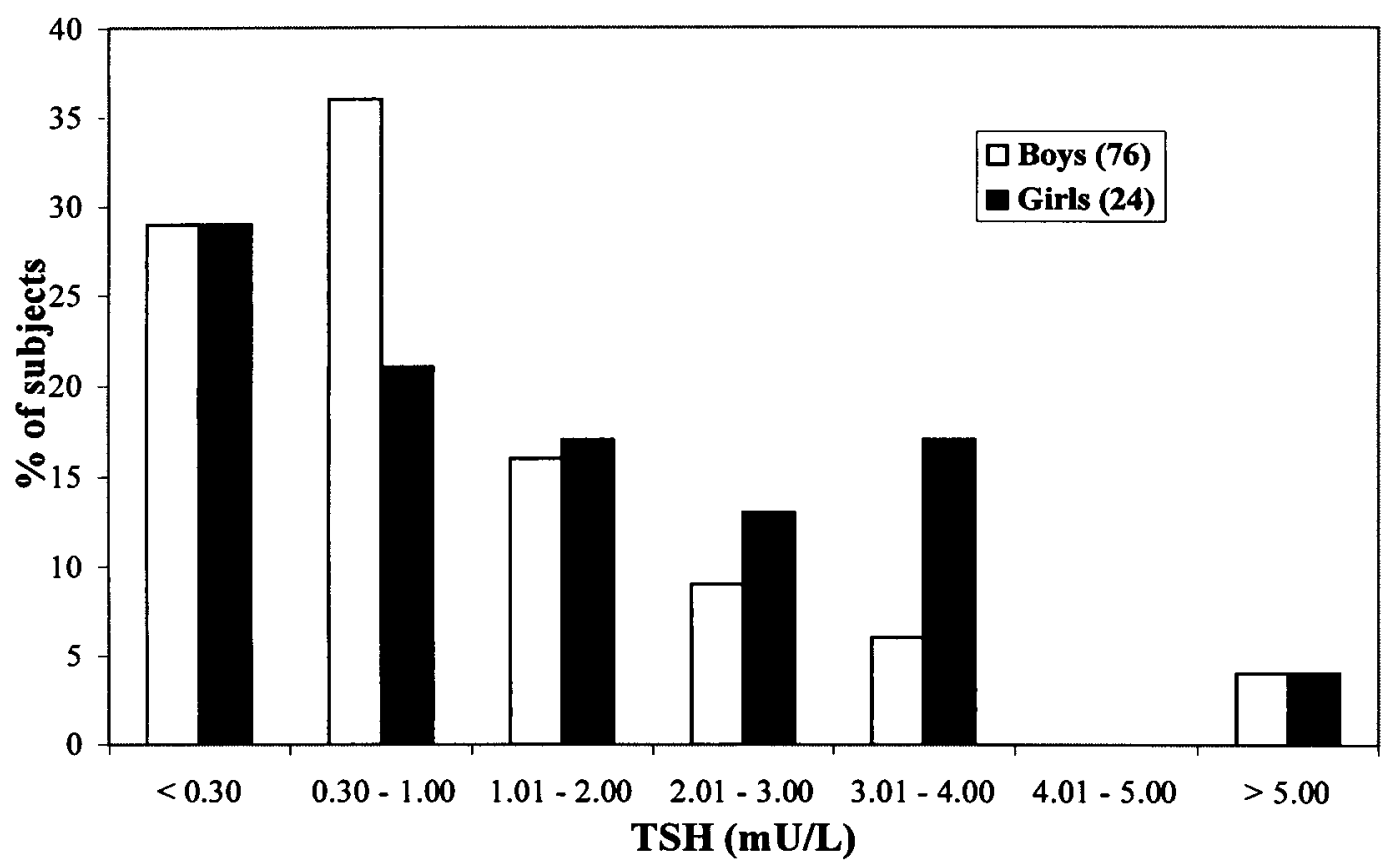

Figure 4 Frequency distribution of TSH $(\mathrm{mU} / \mathrm{l})$ in described ranges in boys and girls from (A) Dang district and (B) Baroda district.

Using criteria recommended by WHO (1) for defining the severity and prevalence of IDD as a public health problem, Gujarat may be labeled as having a severe IDD problem based on clinical measurement of thyroid size, and mild IDD based on biochemical indicators. Thus, the study highlights the complexity of assessing the severity of iodine deficiency in the presence of multiple confounding but interacting variables of not only a lack of iodine but also the presence of malnutrition and high goitrogen intake. 
Table 3 Identification and quantification of different types of flavonoids in pearl millet in Muval and Tentalav villages in Baroda district.

\begin{tabular}{lccc}
\hline & Apigenin $(\mathrm{mg} / \mathrm{kg})$ & Vitexin $(\mathrm{mg} / \mathrm{kg})$ & Glycosyl vitexin \\
\hline Muval & 1.4 & 38.9 & Present \\
Tentalav & 2.8 & 166.5 & Present \\
\hline
\end{tabular}

The Dang district was more severely affected by iodine deficiency than the Baroda district. The median values for thyroid volume were higher in children from the Dang district as compared with those from the Baroda district. Lack of iodine in drinking water, along with known (flavonoids in pearl millet) and unknown goitrogens is probably the explanation for these differences. Nutritional factors may also be responsible, as protein calorie malnutrition (PCM) has been reported to contribute to goiter development. By comparison, despite having adequate iodine in drinking water, Baroda schoolchildren showed a high prevalence of goiter possibly due to the concomitant effects of high intake of dietary goitrogens in their staple diet (various flavonoids identified by us in pearl millet).

In both districts, girls were more severely affected than boys as determined by biochemical indicators of UI and TSH. However, this was not reflected in thyroid size, either determined by palpation or by ultrasonography but a greater number of girls had enlarged TV-for-age. Previous authors had suggested that sex might influence the development of thyroid size. A number of studies based on ultrasonography in iodine-sufficient areas have found that girls have larger thyroids compared with boys during puberty $(4,14)$ whereas others report no difference in thyroid size by sex $(9,10$, 15, 16). Our study showed statistically significant thyroid volume gender differences in children from the Dang district, with boys having greater TV, but clinically this difference was not important. There have been no population normative values for TSH published for this population nor for schoolchildren from an

Table 4 Linear regression analysis response: thyroid volume (calculated by $\mathrm{WHO}$ formula).

\begin{tabular}{lccc}
\hline Parameter & Coefficient & Standard error & $\boldsymbol{P}$ \\
\hline Constant & -47.257 & 14.223 & 0.001 \\
Weight $(\mathrm{kg})$ & -2.519 & 0.789 & 0.002 \\
BMl $\left(\mathrm{kg} / \mathrm{m}^{2}\right)$ & 1.531 & 0.474 & 0.001 \\
District & 8.440 & 1.484 & 0.000 \\
Urinary iodine $(\mu \mathrm{g} / \mathrm{l})$ & 0.018 & 0.008 & 0.029 \\
Nagli* & -8.538 & 1.407 & 0.000 \\
Kharsani oil\# & 6.483 & 1.247 & 0.000 \\
BSA $\left(\mathrm{m}^{2}\right)$ & 105.15 & 27.763 & 0.000 \\
\hline
\end{tabular}

df, difference: $520 ; R^{2}: 0.151$.

*Nagli is a type of cereal consumed by Dang district tribals; \# Kharsani oil - consumed by Dang district tribals. iodine-replete environment. This is an area of further research that is required. Furthermore, the data highlight the at-risk nature of the female population, given that a larger number of women in the child-bearing age group will still be iodine deficient. This is particularly important because iodine deficiency in fetuses and infants can lead to irreversible intellectual deficits with great impact on the population (2). A similar finding of females having lower median UI values than males has also been reported in iodine-replete populations, in the National Health and Nutrition Examination Surveys I and III (17).

We have identified apigenin in pearl millet from the Baroda district and its quantity was almost double in one of the villages (Tentalav). The relatively greater intake of flavonoids in children from Tentalav than those from Muval is reflected in higher median values for thyroid volume. Apigenin, an aglycone of flavonoid glycoside, has been identified from 6-propyl-thiouracil (PTU), an antithyroid drug, but had not previously been reported from pearl millet (18). These previous studies have attributed the potent antithyroid effects of millet to the flavonoids vitexin, glucosyl vitexin and glucosyl orientin, accounting for $67 \%$ of these effects in vitro. Apigenin is 3 to 5 times more active than vitexin, glucosyl vitexin and glucosyl orientin. In our study, flavonoids in the form of apigenin, vitexin and glucosyl vitexin were identified in pearl millet, a staple diet of Baroda schoolchildren. Interestingly, levels of apigenin and vitexin were higher in pearl millet from Tentalav compared with that from Muval (Table 3).

Flavonoids interfere with the synthesis of thyroid hormones not only by inhibiting the thyroid peroxidase enzyme (catalyzing iodide oxidation) and thereby the organification processes, but also by inhibiting the peripheral metabolism of thyroid hormones by acting on the iodothyronine deiodinase enzyme. This greater inhibitory effect is further enhanced by the additive effects exerted by flavonoid metabolites, which are formed after ingestion of mixtures of flavonoid glycoside present in many plant foodstuffs. As a result, the antithyroid effects of flavonoid glycoside present in pearl millet may make a major contribution to, and be primarily responsible for, its antithyroid effects including causation of large goiter in the affected population.

The dissonance of thyroid size and biochemical indicators of iodine deficiency is explained by several factors. First, it may be explained by the difference in the temporal nature of these indicators, where biochemical indicators are short-term markers of iodine deficiency, whereas measures of thyroid size are longer-term indicators. Secondly, thyroid size as determined by palpation underestimates the extent of the problem and is inaccurate in the assessment of grade 1 goiter, and has low specificity and sensitivity in goiters of grades 0 and 1 .

From our study it is apparent that thyroid palpation is of limited value for epidemiological surveys of IDD and is 
Table 5 Comparison of thyroid volume measured by ultrasonography in children from Gujarat as a function of age and sex with WHO, Gutekunst and Switzerland refrence values.

\begin{tabular}{|c|c|c|c|c|c|c|c|}
\hline \multirow{2}{*}{$\begin{array}{l}\text { Age } \\
\text { (years) }\end{array}$} & \multicolumn{4}{|c|}{ 50th percentile } & \multicolumn{3}{|c|}{ 97th percentile } \\
\hline & WHO‡ & Gujarat $†$ & Gutekunst** $^{\star *}$ & Switzerland & WHO‡ & Gujarat $\dagger^{\star}$ & Gutekunst** \\
\hline \multicolumn{8}{|l|}{ Male } \\
\hline 6 & 3.2 & 21.3 & 1.5 & 2.5 & 5.4 & & 3.5 \\
\hline 7 & 3.4 & 25.5 & 1.8 & 2.9 & 5.7 & & 4.0 \\
\hline 8 & 3.7 & 20.8 & 2.0 & 3.5 & 6.1 & & 4.5 \\
\hline 9 & 4.1 & 24.1 & 2.4 & 4.2 & 6.8 & & 5.0 \\
\hline 10 & 4.5 & 28.8 & 2.8 & 4.7 & 7.8 & 53.8 & 6.0 \\
\hline 11 & 5.1 & 27.3 & 3.1 & 6.1 & 9.0 & 55.8 & 7.0 \\
\hline 12 & 5.7 & 24.6 & 3.7 & 5.3 & 10.4 & 45.0 & 8.0 \\
\hline 13 & 6.5 & 26.0 & 4.2 & 7.3 & 12.0 & & 9.0 \\
\hline 14 & 7.3 & 25.2 & 5.0 & 9.6 & 13.9 & & 10.5 \\
\hline 15 & 8.2 & 23.0 & 5.8 & 10.3 & 16.0 & & 12.0 \\
\hline \multicolumn{8}{|l|}{ Female } \\
\hline 6 & 2.9 & 20.8 & 2.2 & 2.5 & 5.0 & & 3.8 \\
\hline 7 & 3.4 & 27.6 & 3.0 & 3.6 & 5.9 & & 4.3 \\
\hline 8 & 3.9 & 22.7 & 3.4 & 3.8 & 6.9 & & 5.0 \\
\hline 9 & 4.4 & 25.6 & 5.0 & 3.9 & 8.0 & 40.0 & 5.3 \\
\hline 10 & 5.0 & 26.0 & 4.0 & 5.3 & 9.2 & 46.8 & 6.7 \\
\hline 11 & 5.7 & 25.0 & 4.2 & 5.7 & 10.4 & 58.3 & 7.8 \\
\hline 12 & 6.3 & 26.0 & 6.5 & 7.7 & 11.7 & 69.8 & 8.6 \\
\hline 13 & 7.0 & 28.9 & 9.9 & 9.6 & 13.1 & & 9.1 \\
\hline 14 & 7.7 & 31.1 & 8.8 & 7.7 & 14.6 & & 11.0 \\
\hline 15 & 8.4 & 20.3 & 9.0 & 9.0 & 16.1 & & 12.2 \\
\hline
\end{tabular}

‡ Source: WHO/ICCIDD (4); ** source Gutekunst et al. (20), Gutekunst \& Martin-Teichert (9); ๆ source: Bürgi et al. (11).

$\dagger$ Highlighted data pertains to present study. ${ }^{*}$ Data available for age groups $9-12$ years only; sample size too small for calculating 97 th percentile for remaining groups.

insensitive in the assessment of schoolchildren. The best clinical indicator for the assessment of the severity and extent of IDD is estimation of thyroid volume by ultrasound $(11,12,19,20)$. The present study highlights that the BSA reference should be preferred to the

Table 6 Comparison of the thyroid volumes by ultrasonography (as a function of BSA) in Gujarat children with WHO reference values.

\begin{tabular}{|c|c|c|c|c|}
\hline \multirow{2}{*}{$\begin{array}{l}\text { BSA } \\
\left(\mathrm{m}^{2}\right)\end{array}$} & \multicolumn{2}{|c|}{ 50th percentile } & \multicolumn{2}{|c|}{ 97th percentile } \\
\hline & WHO‡ & Gujarat $\dagger$ & WHO $\ddagger$ & Gujarat $\dagger^{*}$ \\
\hline \multicolumn{5}{|l|}{ Males } \\
\hline 0.8 & 3.0 & 23.1 & 4.7 & 44.5 \\
\hline 0.9 & 3.2 & 27.9 & 5.3 & 54.7 \\
\hline 1.0 & 3.8 & 25.8 & 6.0 & 47.2 \\
\hline 1.1 & 4.2 & 28.2 & 7.0 & 56.2 \\
\hline 1.2 & 4.9 & 23.2 & 8.0 & \\
\hline \multicolumn{5}{|c|}{ Females } \\
\hline 0.8 & 3.1 & 25.0 & 4.8 & 40.5 \\
\hline 0.9 & 3.4 & 24.2 & 5.9 & 45.5 \\
\hline 1.0 & 4.0 & 27.2 & 7.1 & 79.4 \\
\hline 1.1 & 4.6 & 27.4 & 8.3 & \\
\hline 1.2 & 5.2 & 31.3 & 9.5 & \\
\hline
\end{tabular}

‡Source: WHO/ICCIDD (4).

†Highlighted data pertain to the present study; ${ }^{*} 97$ th percentile could not be calculated for the group of males with $B S A=1.2 \mathrm{~m}^{2}$ and females with BSA $>1.0 \mathrm{~m}^{2}$ due to small sample size.

Note: $9 \%$ of children in the present study group had $B S A<0.8 \mathrm{~m}^{2}$. age-based reference range. The additional utility of thyroid ultrasonography is that it provides an integrated assessment tool for the multiple factors that influence the development of goiter and thus the risk of other IDD.

\section{Acknowledgements}

We acknowledge the assistance given to us by Professor Creswell Eastman, Director, ICPMR, Western Sydney Area Health Services, Westmead Hospital, Westmead, for providing funds for the analysis of urinary iodine, blood TSH and estimation of goitrogens in food stuffs at ICPMR; Dr Karen Byth, Consultant Statistician, Westmead Hospital, Westmead for carrying out the statistical analysis of the data; Dr Gary Ma, Laboratory Manager and Mr Ron Fearnley, Technical Officer, Iodine Laboratory, Department of Diabetes and Endocrinology, Westmead Hospital, Westmead, for their help in laboratory work involving blood spot TSH and urine iodine estimations respectively; and Dr Michael Collins, Laboratory Manager, Division of Analytical Laboratory, ICPMR, Western Sydney Area Health Services, Lidcombe, NSW.

\section{References}

1 World Health Organization, United Nations International Children's Education Fund and International Council for Control of Iodine Deficiency Disorders. Indicators for assessing IDD and their 
control through salt iodisation. Geneva: WHO/NUT/94.6, World Health Organization, 1994.

2 Boyages SC \& Halpern JP. Endemic cretinism: toward a unifying hypothesis. Thyroid 19933 59-69.

3 Source: ICCIDD web site: HYPERLIN http:// www.people.Virginia EDU/ jtd/ iccidd/home.html: What is new? June-July 1999, monthly update.

4 World Health Organization and International Council for Control of Iodine Deficiency Disorders, WHO/ICCIDD. Recommended normative values for thyroid volume in children aged 6-15 years. Bulletin of the World Health Organization 199775 95-97.

5 Pandav CS. IDD in South-East Asia. In S.O.S. for a Billion, the Conquest of IDD, ch 14, pp 220. Eds BS Hetze \& CS Pandav. Delhi: Oxford University Press, 1994.

6 Desai V \& Kumar P. In IDD in Gujarat. Proceedings of Workshop cum Seminar on IDD held on 8 January 1994 at Department of PSM, Government Medical College, Surat. Assisted by UNICEF and published by Surat Chhapaighar, 1995.

7 DuBois D \& DuBois EF. Clinical colorimetry. A formula to estimate the approximate surface area if height and weight be known. Archives of Internal Medicine 191617863.

8 Ueda D. Normal volume of the thyroid gland in children. Journal of Clinical Ultrasound 199018 455-462.

9 Gutekunst R \& Martin-Teichert H. Requirements for goiter surveys and the determination of thyroid size. In Iodine Deficiency in Europe. A Continuing Concern, pp 109-118. Eds F Delange, JT Dunn \& D Glinoer. New York: Plenum Press, 1993.

10 Aghini-Lombardi F, Antonangeli L, Pinchera A, Leoli F, Rago T \& Vittai P et al. Effect of iodized salt on thyroid volume of children living in an area previously characterized by moderate iodine deficiency. Journal of Clinical Endocrinology and Metabolism 1997 82 1136-1139.

11 Bürgi H, Portmann L, Poboda J, Vertongen F \& Srbecky M. Thyroid volume and urinary iodine in Swiss schoolchildren, 17 years after improved prophylaxis of iodine deficiency. European Journal of Endocrinology 1999140 104-106.

12 Özgen A, Erol C, Kaya A, Özmen M, Akata D \& Akhan O. Interobserver and intraobserver variations in sonographic measurement of thyroid volume in children. European Journal of Endocrinology 1999140 328-333.

13 Sandell EB \& Kolthoff IM. Micro determination of iodine by a catalytic method. Microchemica Acta 19371 9-25.

14 Delange F, Benker G, Caron Ph, Eber O, Ott W, Peter F et al. Thyroid volume and urinary iodine in European schoolchildren: standardization of values for assessment of iodine deficiency. European Journal of Endocrinology 1997136 180-187.

15 Ivarsson SA, Persson PH \& Ericsson UB. Thyroid gland volume as measured by ultrasonography in healthy children and adolescents in non-iodine deficient area. Acta Paediatrica Scandinavica $198978633-634$.

16 Xu F, Sullivan K, Houston R, Zhao J, May W \& Maberly G. Thyroid volumes in US and Bangladeshi schoolchildren: a comparison with European schoolchildren. European Journal of Endocrinology $1999140498-504$.

17 Hollowell JG, Staehling NW, Hannon WH, Flanders DW, Gunter EW \& Maberly Gf et al. Iodine nutrition in the United States: trends and public health implications. Iodine excretion data from NHANES I and NHANES III surveys (1971-1974 and 19881994). Journal of Clinical Endocrinology and Metabolism 199883 3401-3408.

18 Lindsay RH, Gaitan E \& Cooksey RC. Pharmacokinetics and intrathyroidal effects of flavonoids. In Environmental Goitrogenesis, ch 4, pp 44-54. Ed E Gaitan. Florida, USA: CRC Press Inc, 1989.

19 Rasmussen SN \& Hjorth L. Determination of thyroid volume by ultrasonic scanning. Journal of Clinical Ultrasound 19742 143147.

20 Gutekunst R, Smolarek H \& Scriba P. Comparison of thyroid volumes of schoolchildren in Federal Republic of Germany and Sweden. In Thyroid Disorders Associated with Iodine Deficiency and Excess, vol 22, pp 37-38. Eds R Hall \& J Köbberling. New York: Raven Press 1988.

Received 6 July 1999

Accepted 6 March 2000 